$$
\angle A-S 4 B--96-5 /-
$$

ALL - RUSSIAN SCIETIFIC - RESEARCH INSTITUTE OF $p+, 1$ EXPERIMENTAL PHYSICS

\author{
RECFIVED \\ APR 241996 \\ OSTI
}

A.V.Pevnitsky, V.P.Solovyev, A.I.Abakumov, P.N.Nizovtsev, V.S.Sen'kov, P.B.Loginov

\title{
COMPUTATION OF INITIAL STAGE OF RBMK REACTOR FUEL CHANNEL VESSEL RUPTURE
}

\section{Report on Phase 4 of Task Order 007 under University of}

California - VNIIEF Subcontract $100002 \mathrm{P} 0004-95$

LANL Technical Coordinator F.Motley 1995
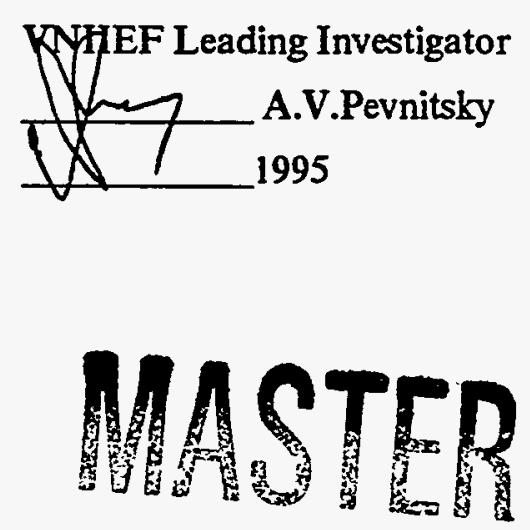

\section{-1995 -}




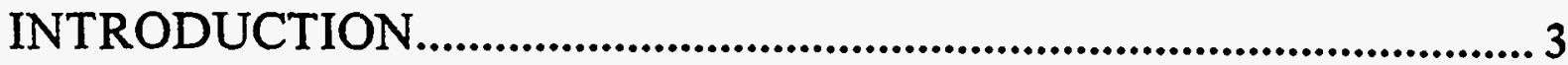

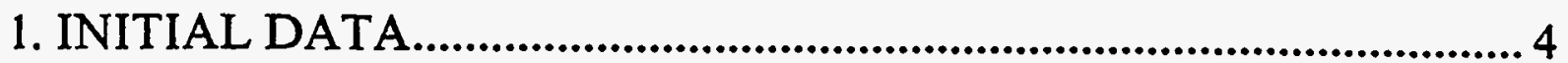

2. PROBLEM FORMULATION .................................................. 15

3. COMPUTED RESULTS ........................................................ 17

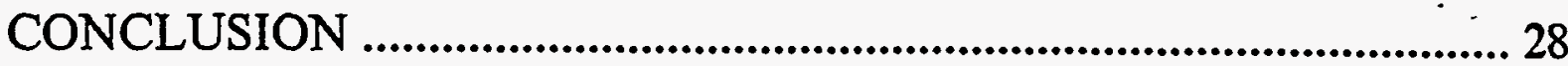

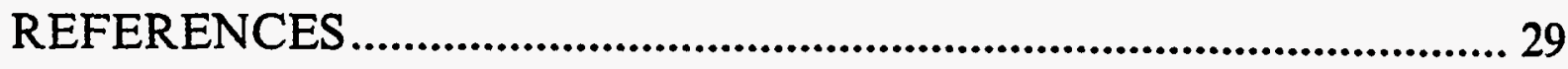

\section{DISCLAIMER}

This report was prepared as an account of work sponsored by an agency of the United States Government. Neither the United States Government nor any agency thereof, nor any of their employees, makes any warranty, express or implied, or assumes any legal liability or responsibility for the accuracy, completeness, or usefulness of any information, apparatus, product, or process disclosed, or represents that its use would not infringe privately owned rights. Reference herein to any specific commercial product, process, or service by trade name, trademark, manufacturer, or otherwise does not necessarily constitute or imply its endorsement, recommendation, or favoring by the United States Government or any agency thereof. The views and opinions of authors expressed herein do not necessarily state or reflect those of the United States Government or any agency thereof. 


\section{INTRODUCTION}

Objective of this work is estimation of temperature and time characteristics for rupture of the zirconium pipe which is the RBMK reactor fuel channel (FC) vessel under emergencies. As an emergency the zirconium pipe temperature rise process is considered which results in loss of pipe material strength properties and pipe rupture under the action of internal pressure $\mathrm{P}=80 \mathrm{MPa}$.

The work was carried out under Task Order 007 of University of California VNIIEF Subcontract $N 20002 \mathrm{P0004-95.}$

The problem formulation is stated in Protocol (Task 3, Appendix 3) of the Russian-American Workshop which was held in December, 1994 in Los Alamos [1]. Physical-mechanical and geometry characteristics of structure elements (FC vessel with graphite ring and graphite slug) are presented by NIKIET [2].The temperature mode of the structure is taken in conformity with the NIKIET data obtained with the RELAP5/MOD3 code [2].

Numerical simulation of structure element behavior in an emergency is performed using the DRAKON program comlex oriented to solving strength problems for complex spatial structures at intense dynamic loading.

The "DRAKON" program comlex is described and compared with similar western codes in its capabilities in $[3,4]$.

The authors thank NIKIET employees Yu.V.Nikitina, V.D.Baldina, A.A.Petrova and V.D.Rodina for the presented data and useful discussions. 


\section{INITIAL DATA}

The initial data for the computations are presented by NIKIET. The sketch of structure cross section at the anticipated rupture point is shown in Fig.1.

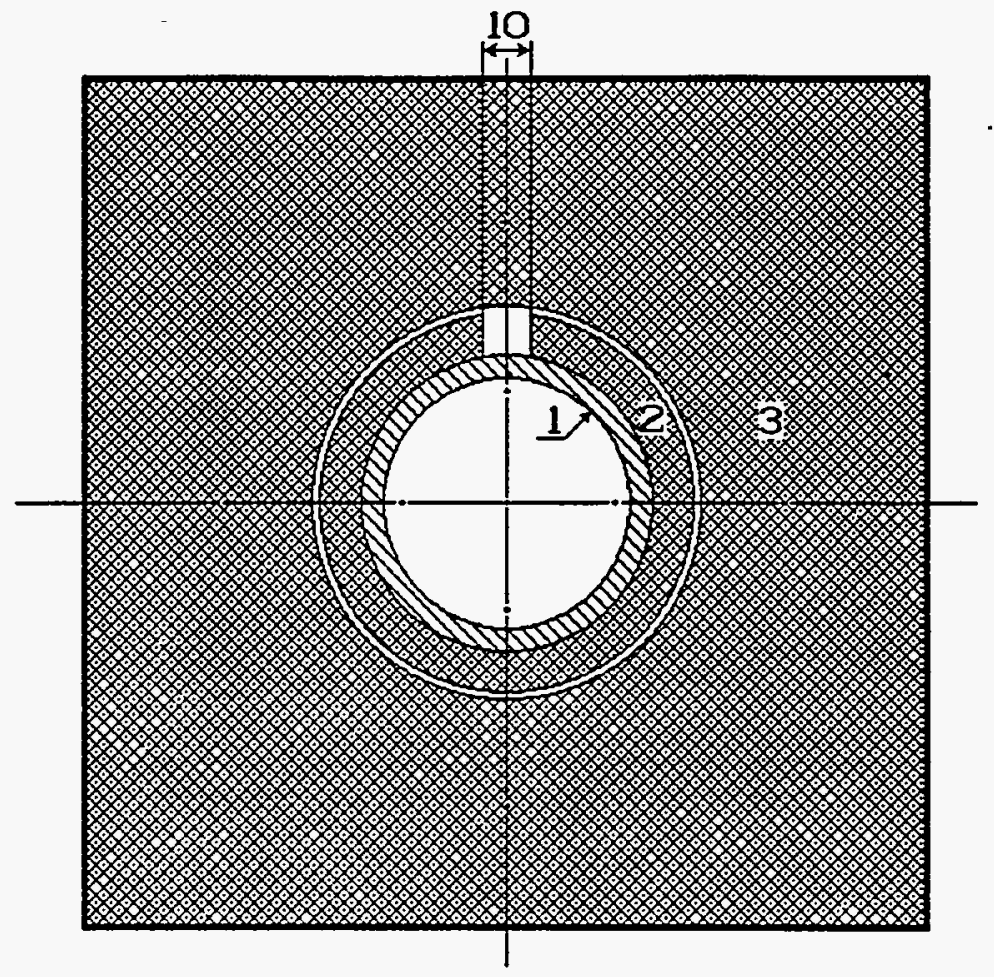

Fig.1. Scetch of graphite ring and graphite slug fuel channel vessel cross section.

1 - zirconium pipe $88 \mathrm{~mm}$ in outside diameter and $4 \mathrm{~mm}$ in wall thickness;

2 - graphite ring $11 \mathrm{~mm}$ in outside diameter;

3 - graphite slug $250 \times 250 \mathrm{~mm}$ in cross section (slug height is $600 \mathrm{~mm}$ ). Diameter of slug hole is $114 \mathrm{~mm}$. Clearances between the slugs in the initial state are $1.5 \mathrm{~mm}$.

Mechanic characteristics for graphite and zirconium pipe are given in Table 1 and in Figs.2...10 (in Figs.4...8 U - sample tension rate). 
Table 1

\begin{tabular}{|l|c|c|}
\hline & $\begin{array}{l}\text { Type GR-280 } \\
\text { graphite }\end{array}$ & $\begin{array}{l}\text { Type GR1-1-280 } \\
\text { graphite }\end{array}$ \\
\hline Density $\left(\mathrm{g} / \mathrm{cm}^{3}\right)$ & 1.71 & 1.78 \\
Young modulus $(\mathrm{GPa})$ & $6.5 / 5.0$ & $15.0 / 10.0$ \\
Thermal expansion factor $\left(10^{-6} 1 /{ }^{\circ} \mathrm{C}\right)$ & $4.0 / 5.4$ & $4.9 / 6.2$ \\
Compression ultimate strength $(\mathrm{MPa})$ & $34.0 / 24.0$ & $42.2 / 45.0$ \\
Ultimate tension (MPa) & $7.6 / 6.0$ & $10.5 / 8.5$ \\
Compression ultimate strain(\%) & $1.6 / 2.0$ & $1.3 / 1.5$ \\
Tension ultimate strain(\%) & $0.2 / 0.2$ & $0.17 / 0.18$ \\
\hline
\end{tabular}

In Table 1 the numerator denotes the characteristic value along the shaping axis, the denominator - in the perpendicular direction. 


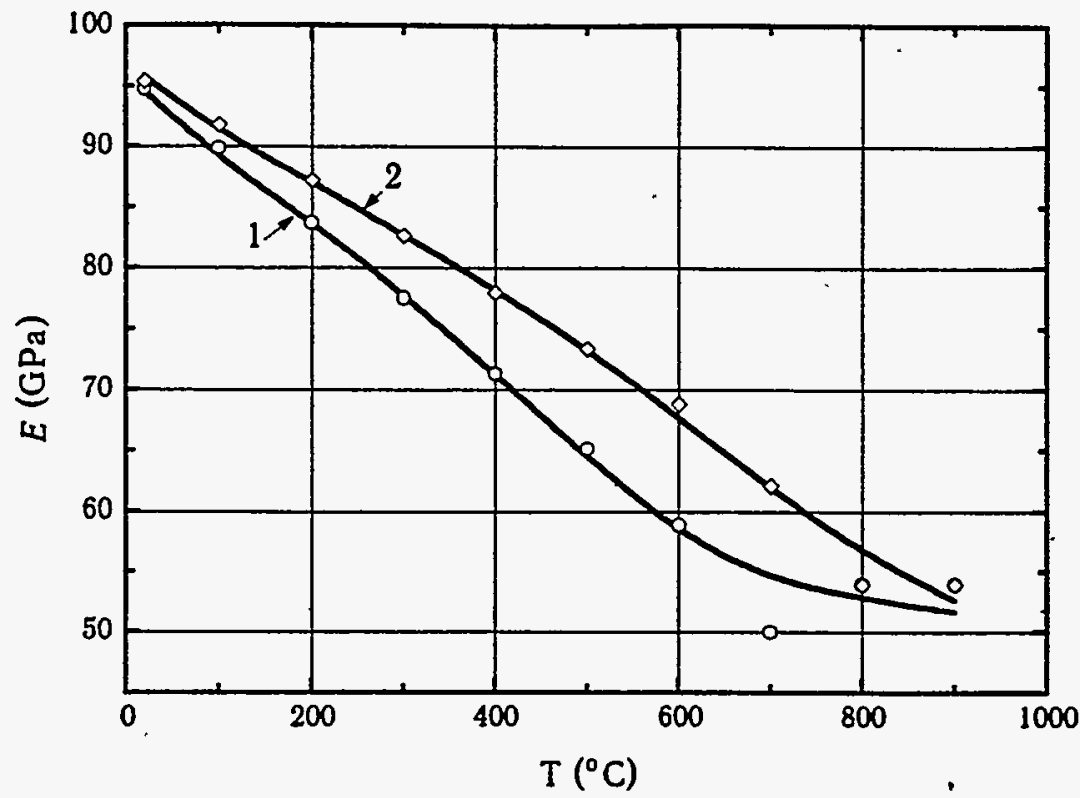

Young modulus.

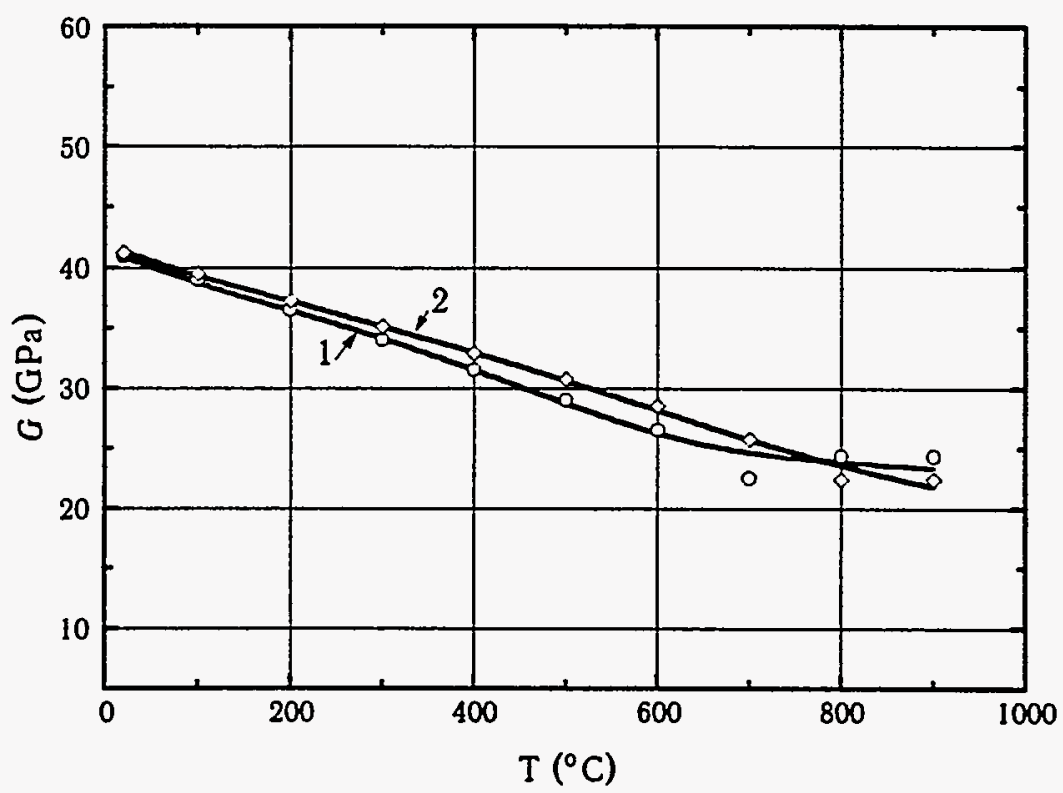

Shear modulus

Fig.2. Mechanical properties of zirconium pipe material (in the annealed state) vs temperature.

1 - the characteristic value in the direction parallel to workpiece shaping axis;

2 - the characteristic value in the direction perpendicular to the workpiece shaping axis. 


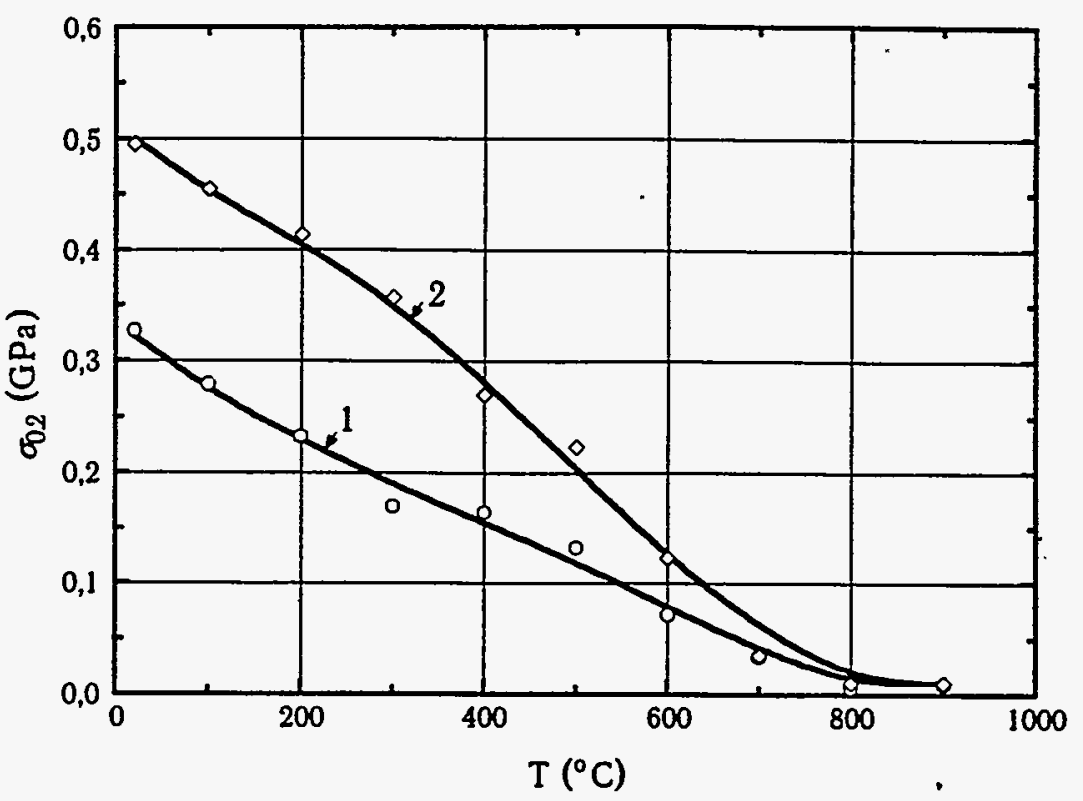

Material yield strength.

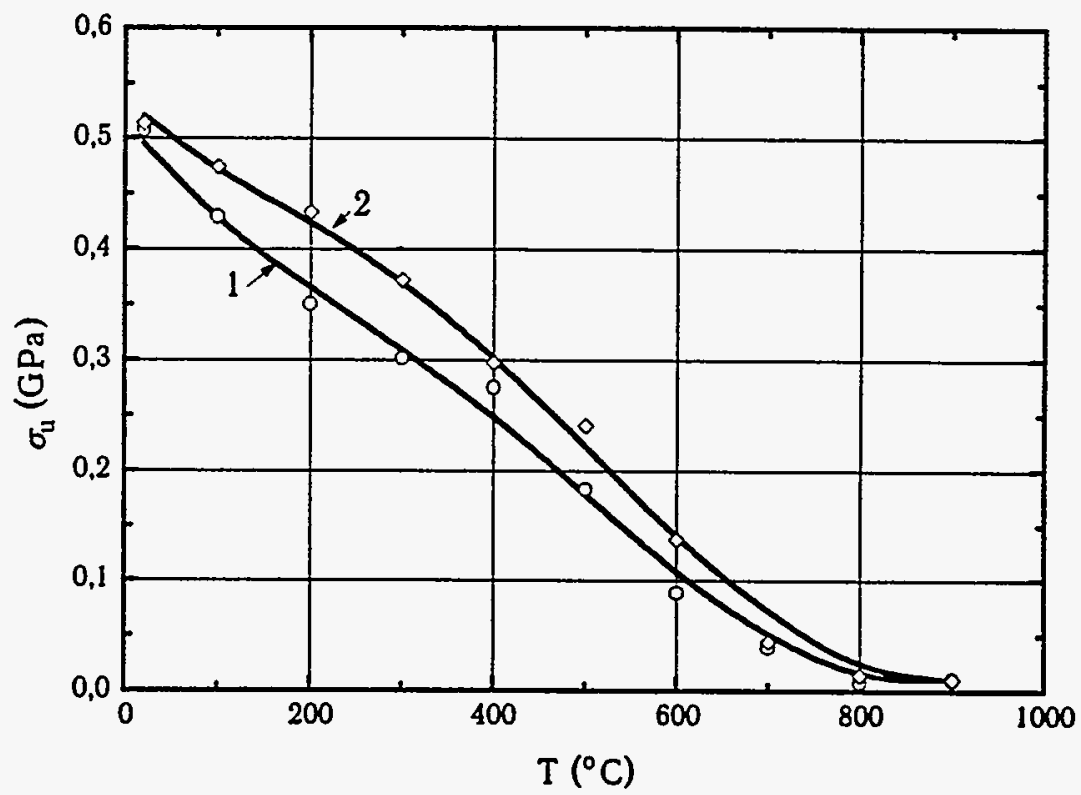

Ultimate tension value.

Fig.3. Mechanical properties of zirconium pipe material (in the annealed state) vs temperature.

1 - the characteristic value in the direction parallel to workpiece shaping axis;

2 - the characteristic value in the direction perpendicular to the workpiece shaping axis. 


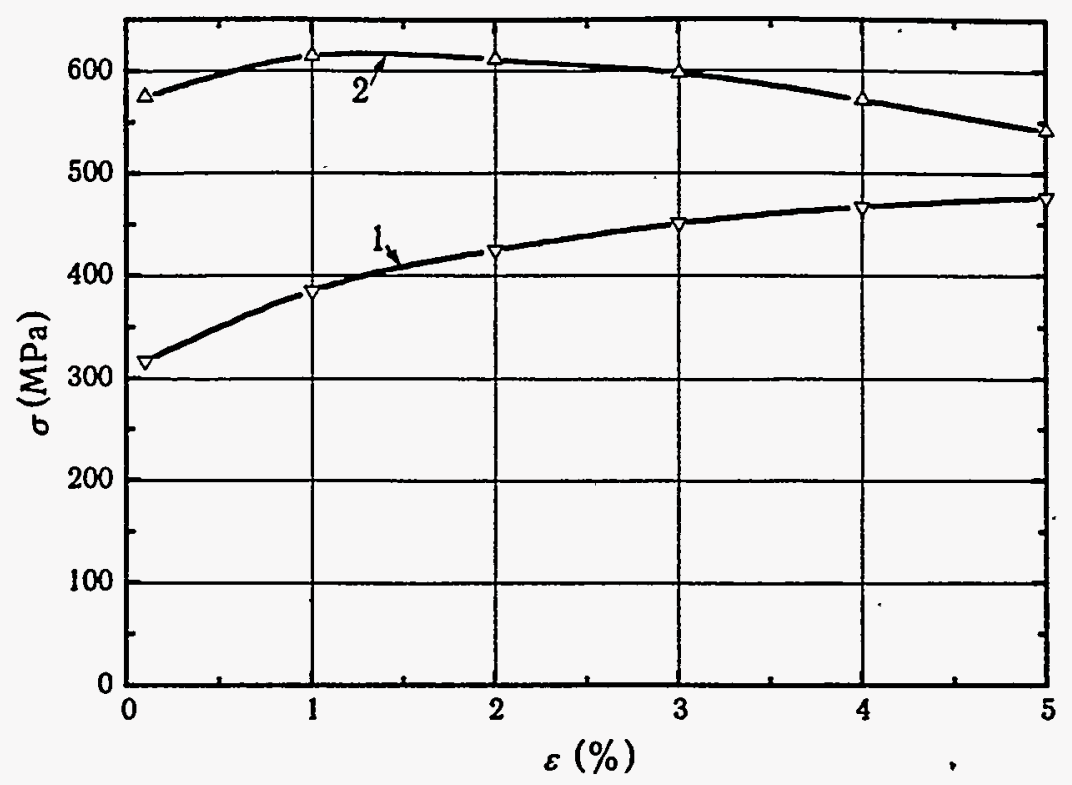

Testing temperature $20^{\circ} \mathrm{C}$.

1 - transverse direction of sample cutting, $\mathrm{U}=1 \mathrm{~mm} / \mathrm{min}$.

2 - longitudinal direction of sample cutting, $U=1 \mathrm{~mm} / \mathrm{min}$.

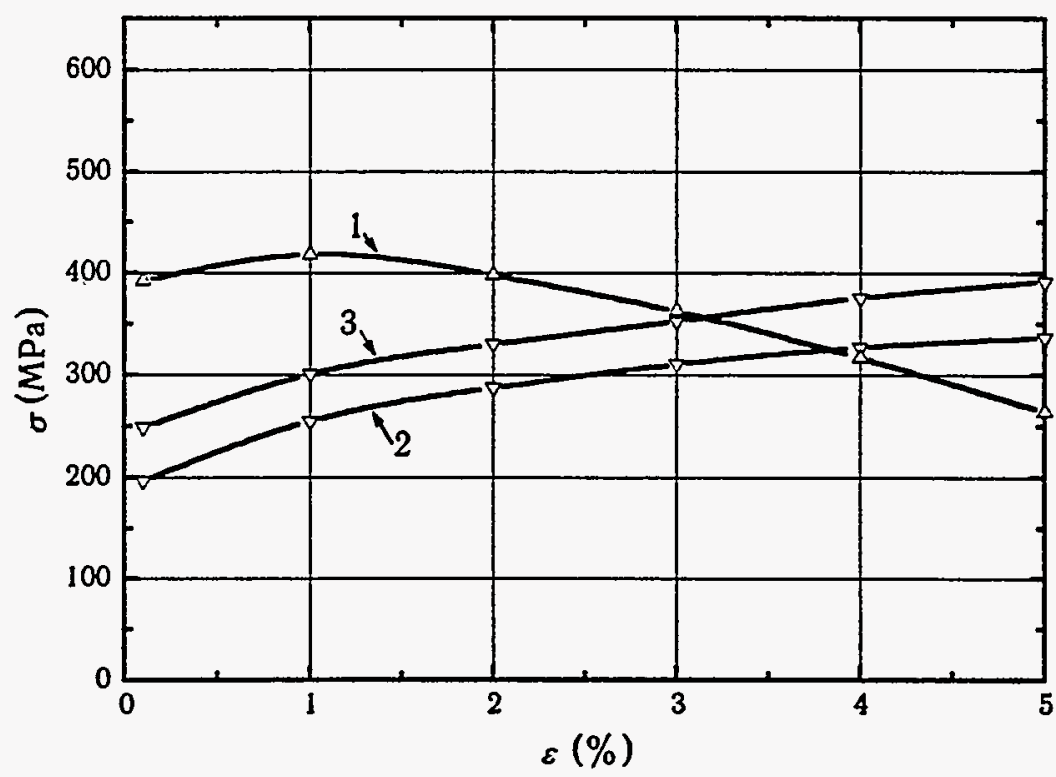

Testing temperature $200^{\circ} \mathrm{C}$.

1 - transverse direction of sample cutting, $U=1 \mathrm{~mm} / \mathrm{min}$.

2 - longitudinal direction of sample cutting, $U=1 \mathrm{~mm} / \mathrm{min}$.

3 - longitudinal direction of sample cutting, $U=10 \mathrm{~mm} / \mathrm{min}$.

Fig.4. Plot of zirconium pipe material strain vs time. 


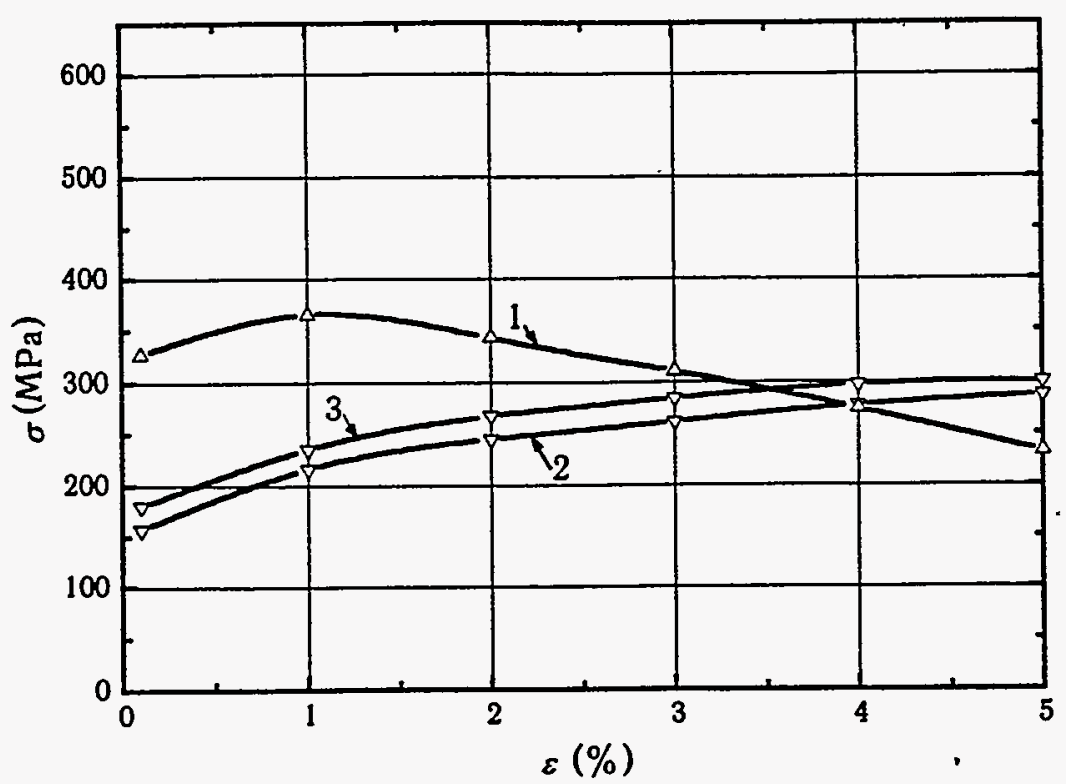

Testing temperature $300^{\circ} \mathrm{C}$.

1 - transverse direction of sample cutting, $U=1 \mathrm{~mm} / \mathrm{min}$

2 - longitudinal direction of sample cutting, $U=1 \mathrm{~mm} / \mathrm{min}$.

3 - longitudinal direction of sample cutting, $U=10 \mathrm{~mm} / \mathrm{min}$.

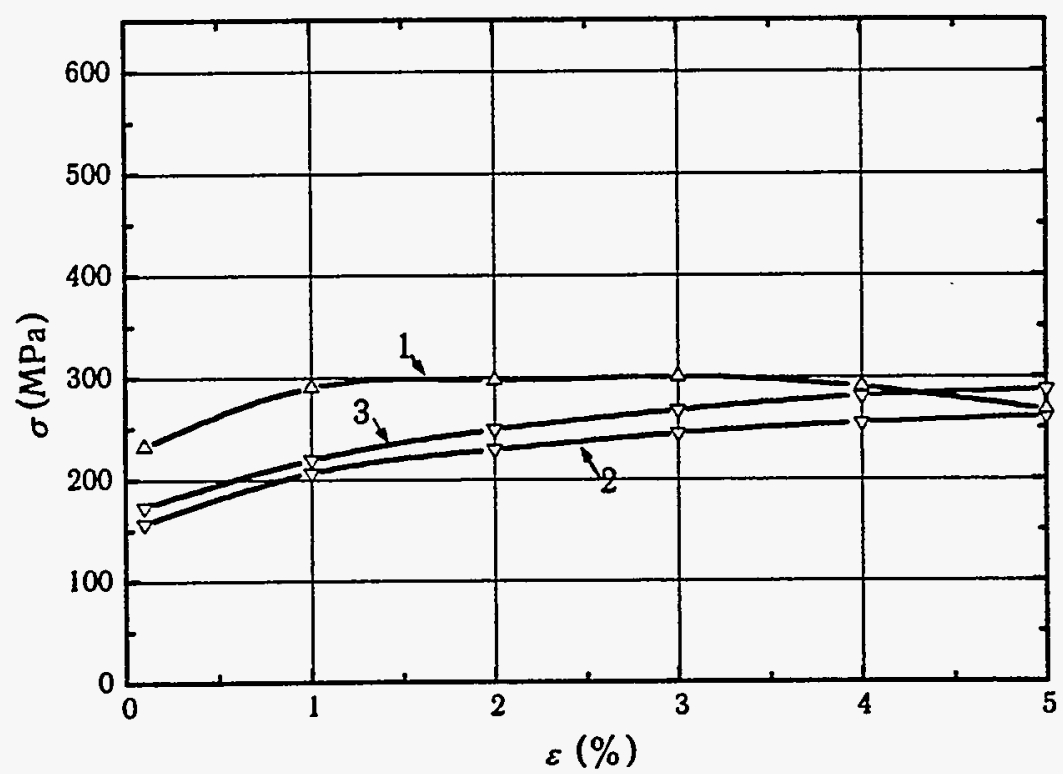

Testing temperature $400^{\circ} \mathrm{C}$.

1 - transverse direction of sample cutting, $U=1 \mathrm{~mm} / \mathrm{min}$

2 - longitudinal direction of sample cutting, $U=1 \mathrm{~mm} / \mathrm{min}$.

3 - longitudinal direction of sample cutting, $U=10 \mathrm{~mm} / \mathrm{min}$.

Fig.5. Plot of zirconium pipe material strain vs time. 


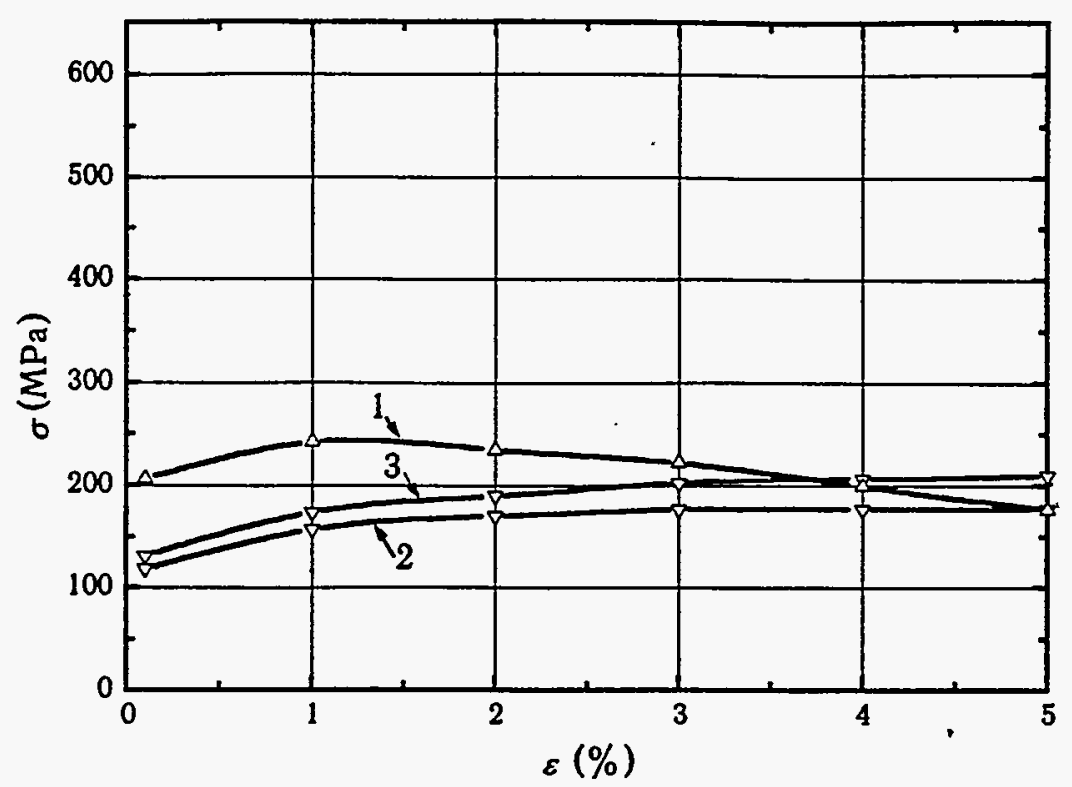

Testing temperature $500^{\circ} \mathrm{C}$.

1 - transverse direction of sample cutting, $U=1 \mathrm{~mm} / \mathrm{min}$.

2 - longitudinal direction of sample cutting, $U=1 \mathrm{~mm} / \mathrm{min}$.

3 - longitudinal direction of sample cutting, $U=10 \mathrm{~mm} / \mathrm{min}$.

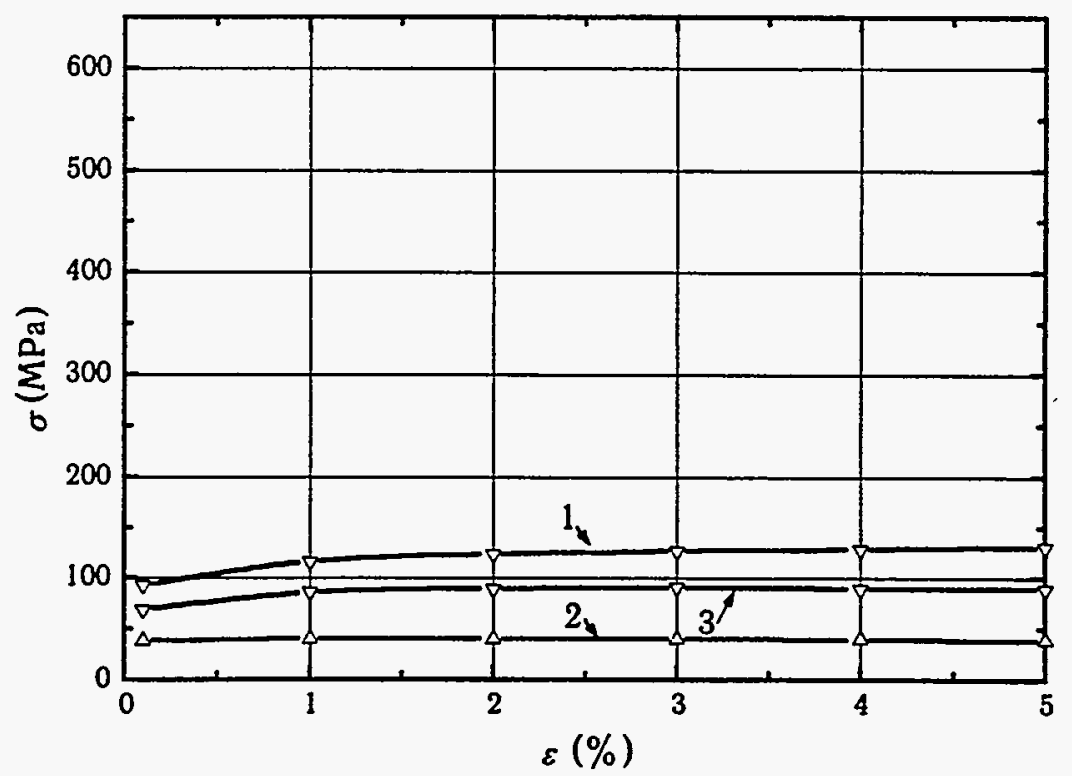

Testing temperature $600^{\circ} \mathrm{C}$.

1 - transverse direction of sample cutting, $\mathrm{U}=1 \mathrm{~mm} / \mathrm{min}$.

2 - longitudinal direction of sample cutting, $U=1 \mathrm{~mm} / \mathrm{min}$.

3 - longitudinal direction of sample cutting, $U=10 \mathrm{~mm} / \mathrm{min}$.

Fig.6. Plot of zirconium pipe material strain vs time. 


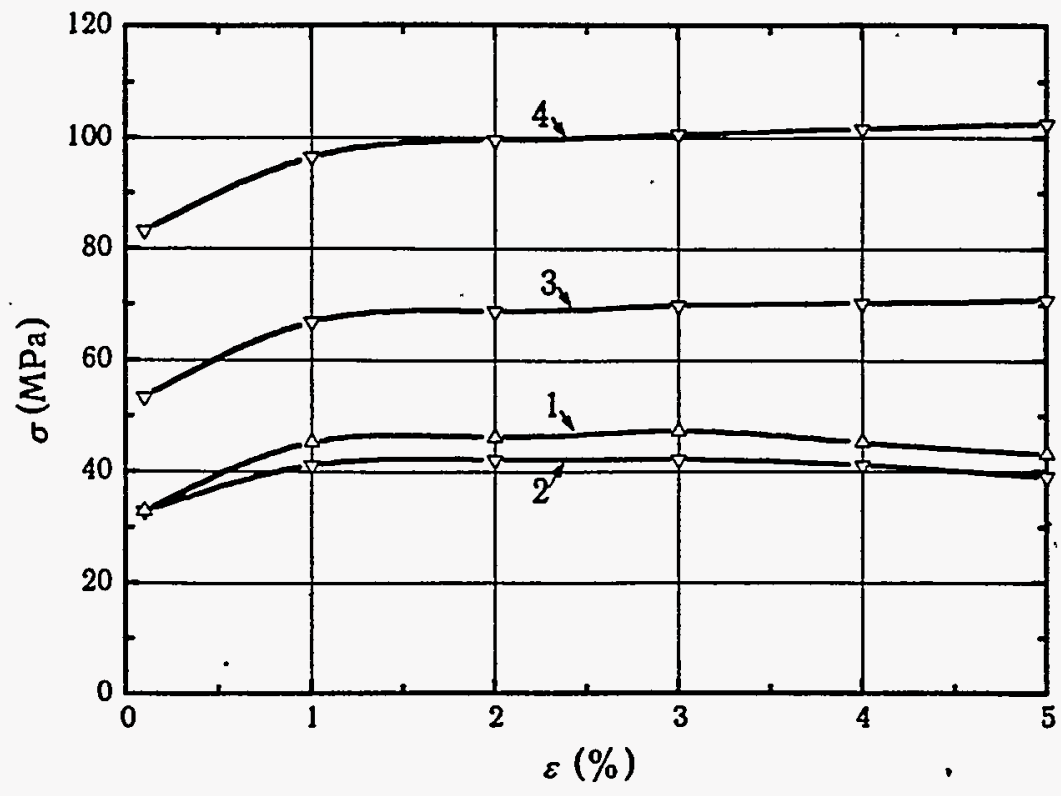

Testing temperature $700^{\circ} \mathrm{C}$.

1 - transverse direction of sample cutting, $U=1 \mathrm{~mm} / \mathrm{min}$.

2 - longitudinal direction of sample cutting, $U=1 \mathrm{~mm} / \mathrm{min}$.

3 - longitudinal direction of sample cutting, $U=10 \mathrm{~mm} / \mathrm{min}$.

4 - longitudinal direction of sample cutting, $U=50 \mathrm{~mm} / \mathrm{min}$.

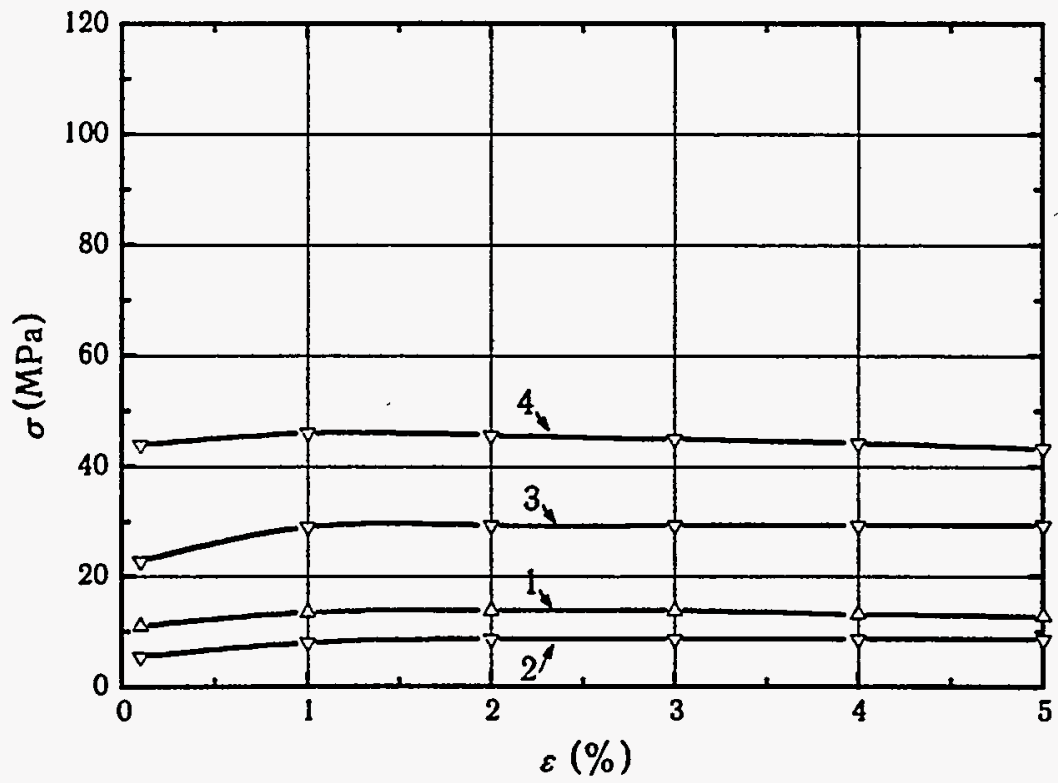

Testing temperature $800^{\circ} \mathrm{C}$.

1 - transverse direction of sample cutting, $U=1 \mathrm{~mm} / \mathrm{min}$.

2 - longitudinal direction of sample cutting, $U=1 \mathrm{~mm} / \mathrm{min}$.

3 - longitudinal direction of sample cutting, $U=10 \mathrm{~mm} / \mathrm{min}$.

4 - longitudinal direction of sample cutting, $U=50 \mathrm{~mm} / \mathrm{min}$.

Fig.7. Plot of zirconium pipe material strain vs time. 


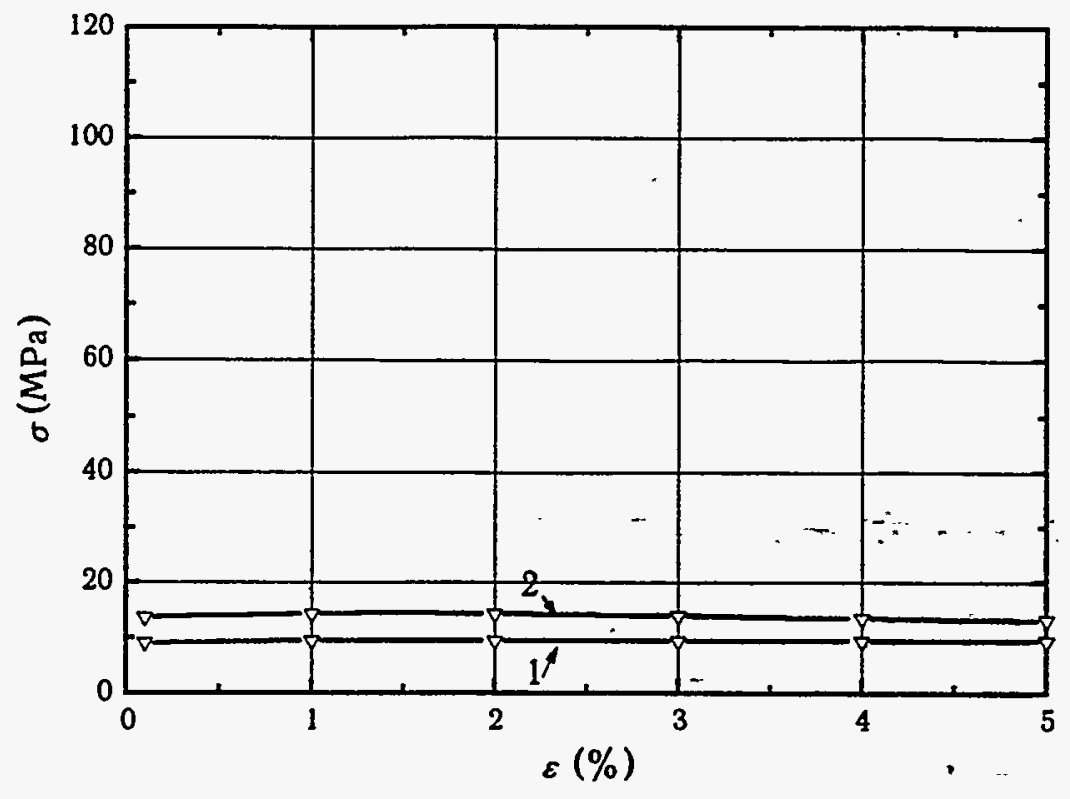

Testing temperature $900^{\circ} \mathrm{C}$.

1 - transverse direction of sample cutting, $U=1 \mathrm{~mm} / \mathrm{min}$.

2 - longitudinal direction of sample cutting, $U=10 \mathrm{~mm} / \mathrm{min}$.

Fig.8. Plot of zirconium pipe material strain time. 


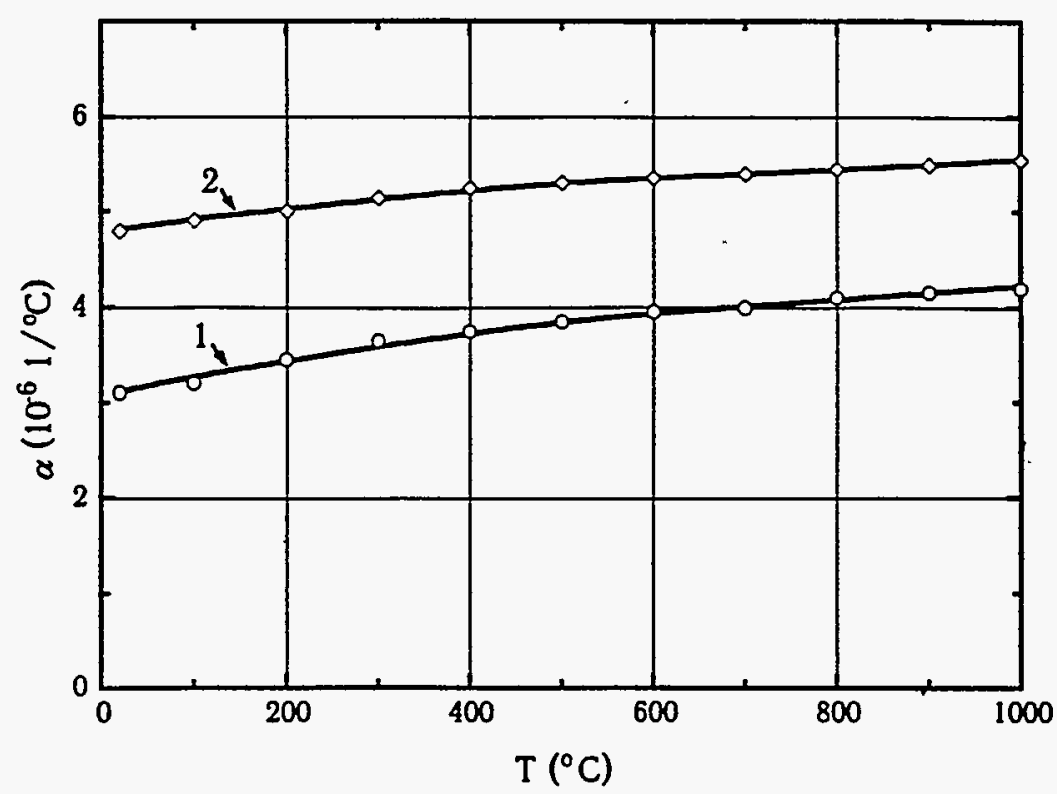

GR-280 material.

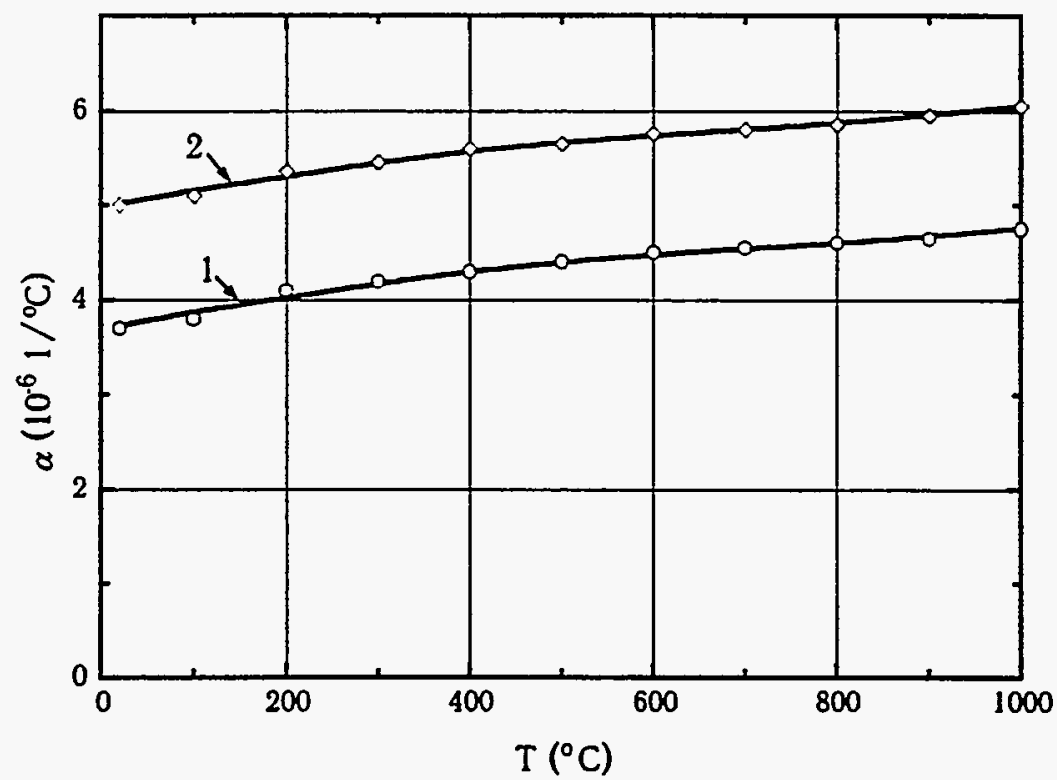

GRP-1-280 material.

Fig.9. The value of graphite thermal expansion factor at higher temperature.

1 - the characteristic value in the direction parallel to the workpiece shaping axis;

2 - the characteristic value in the direction perpendicular to the workpiece shaping axis. 


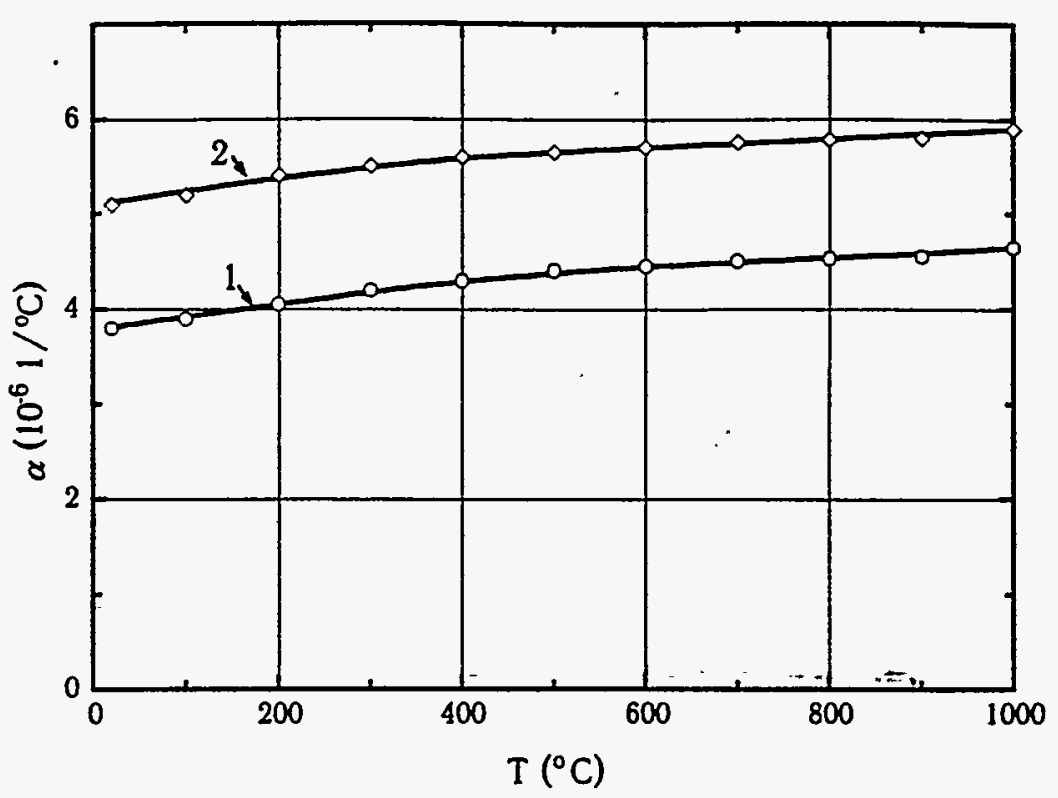

GRP-2-125 material

Fig. 10.The value of graphite thermal expansion factor at higher temperature (sleeves, rings).

1 - the characteristic value in the direction parallel to the workpiece shaping axis;

2 - the characteristic value in the direction perpendicular to the workpiece shaping axis. 


\section{PROBLEM FORMULATION}

The objective of numerical simulation of structure element behavior in an emergency is estimation of temperature at which zirconium pipe rupture takes place and time characteristics of the initial stage of the rupture process. In this paper we do not consider impact on a steam jet appearing at pipe rupture. Urgent is also the issue of destroyed structure element effect on neighboring slugs which can result in their fracture. In this case fracturing can become of chain reaction character.

The formulated problem was solved using the DRAKON program complex $[3,4]$ in two-dimensional setting-up (plane strained state).

From the analysis of acting loading (time variation in pipe temperature determined by the RELAP5/MOD3 code [2]) it follows that until the limiting state is reached the strain process is of static character. Time variation rate of temperature is $\sim 3^{\circ} \mathrm{C} / \mathrm{sec}$. When ultimate loading (pipe heating which results in loss of pipe material strength properties) has been reached the strain process becomes of dynamic character.

The numerical simulation was performed using equations of dynamics which allows to properly describe the transition from the static strain mode to the dynamic: the structure element destruction process. To rule out unreasonable expenditures of computer time during which structure elements are strained in the static mode a time scale factor was introduced to the computation. Temperature dependences of mechanical characteristics: $E(T)$ - Young modulus; $G(T)$ - shear modulus were taken in conformity with the NIKIET data [2] and are given in Section 1 of this report. The computations were performed under assumption of isotropic behavior of element materials. Strain strengthening of pipe material and anisotropy of graphite strength properties at tension and compression are taken into account. Fracture of material is modeled as reduction in strength (yield strength) depending on plastic strain value. In the general case the yield strength dependence assumed in the computation is of the form: 
for pipe

$$
\sigma=\sigma_{0.2} \cdot\left(1+\left(\sigma_{u} / \sigma_{0.2}-1\right) \cdot\left(1-\exp \left(-C_{1} \cdot \varepsilon_{i}^{p}\right)\right)\right) \cdot \exp \left(-C_{2} \cdot\left(\varepsilon_{i}^{p}\right)^{2}\right)
$$

for graphite:

$$
\begin{aligned}
& \sigma=\sigma_{u}^{s} \cdot\left(1+\left(\sigma_{u}^{c} / \sigma_{u}^{s}-1\right)\right) \cdot \varphi(P) \cdot \exp \left(-C_{3} \cdot\left(\varepsilon_{i}^{\mathrm{p}}\right)^{2}\right) \\
& \varphi(P)=1-\exp \left(C_{4} \cdot P\right), \quad P \geq 0 \\
& \varphi(P)=0, \quad P<0
\end{aligned}
$$

Here: $\sigma_{0.2}-$ material yield strength; $\sigma_{u}-$ ultimate strength; $\varepsilon_{\mathrm{i}}^{\mathrm{p}}-$ intensity of plastic strains; $\mathrm{P}$ - pressure; $\mathrm{C}_{\mathrm{i}}$ - constans. The superscript "s" denotes that this characteristic is determined at tension, "c" - at compression.

Owing to the fact that there is no complete information available on strength parameters under the conditions of complex strained state at the dynamic strain mode, as well as criterion data on dynamic fracture at high temperatures are not known the obtained numerical results are of tentative character and require further specification. 


\section{COMPUTED RESULTS}

The computational scheme of the structure in the form-of the difference grid at initial time is shown in Fig.11.

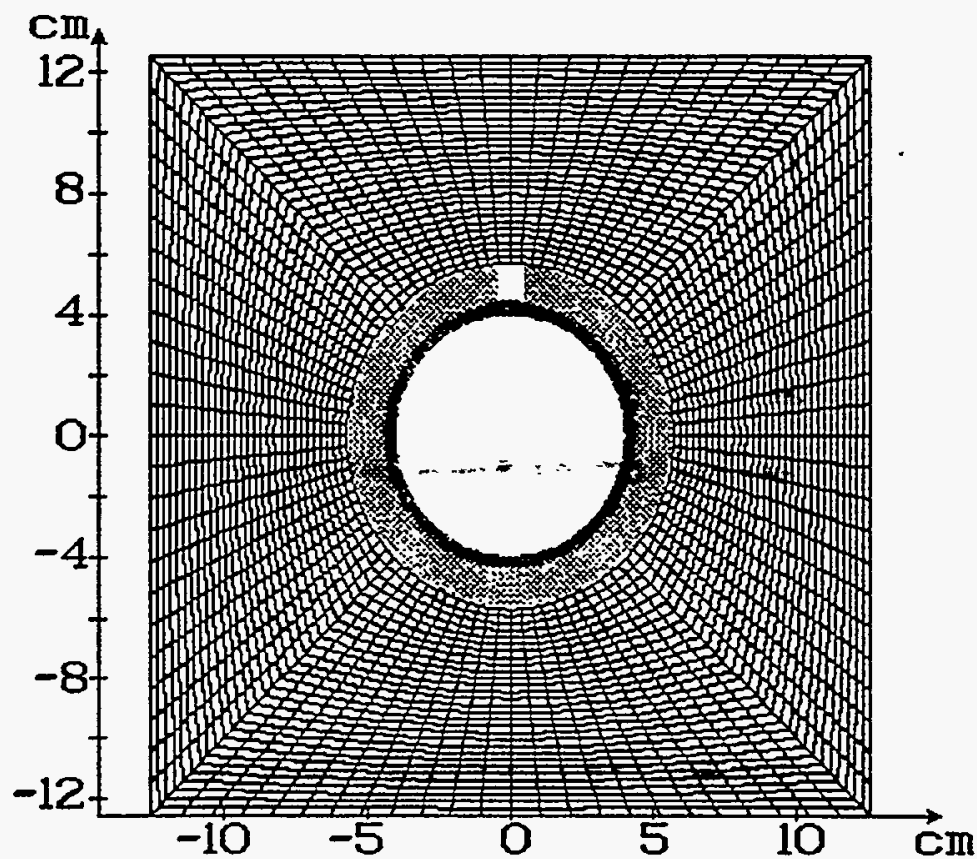

Fig.11. Computational scheme of the structure.

Owing to absence of strength parameters for the structure elements at strain under the conditions close to those which take place during zirconium pipe rupture, a computation series was performed with variation in the limiting values of the element material strength parameters.

According to the NIKIET experimental data [1] ultimate strain of the zirconium pipe in the static strain mode at $600 \div 700^{\circ} \mathrm{C}$ temperatures is $\sim 100 \div 200 \%$. In the first computation variant the yield strength dependence for pipe material was taken with account of this result. For graphite the strain value for which its fracture begins was taken equal to $\sim 1 \%$. Figs.12...14 present computed structure shapes for different times after intense plastic flow of pipe material has begun. These figures also show plastic strain intensity distribution. Temperature at which this effect takes place, according to computed results, is $\sim 665^{\circ} \mathrm{C}$. As it follows from the computed results, due to interaction 
of the expanding pipe with the graphite ring, the latter fractures. Graphite which has lost its strength fills the free space around the pipe and decelerates its motion. Eventually plastic strain growth stops having not reached the ultimate value. Thus, in this computation variant pipe rupture was not fixed.

At dynamic strain ultimate strain of materials, as a rule, is considerably lower than the corresponding static value. In the next computation variant the ultimate strain value for which loss of material strength takes place when it is exceeded was taken equal to $5 \%$. Figs.15...17 present computed structure shapes for different times. As it is seen from the computed results, in this case local increase in plastic strain of the pipe in the region of the graphite ring joint takes place which eventually leads to zirconium pipe rupture at this point. The temperature at which pipe rupture occurs, like in the previous computation variant, is $\sim 665^{\circ} \mathrm{C}$. The loss of zirconium pipe strength results in graphite ring and graphite slug rupture. Velocity of the side surface of the scattering graphite slug up to closure of the clearance with the neighboring slug $(\Delta=1.5 \mathrm{~mm})$ is $\sim 3.2 \mathrm{~m} / \mathrm{s}$.

In the third computation variant, in contrast te the previous variant, the value of graphite ultimate strain was increased up to $10 \%$. The results of this computation variant on the whole agree with those of the previous variant in the character of zirconium pipe rupture and graphite element behavior, Figs.18...20. 

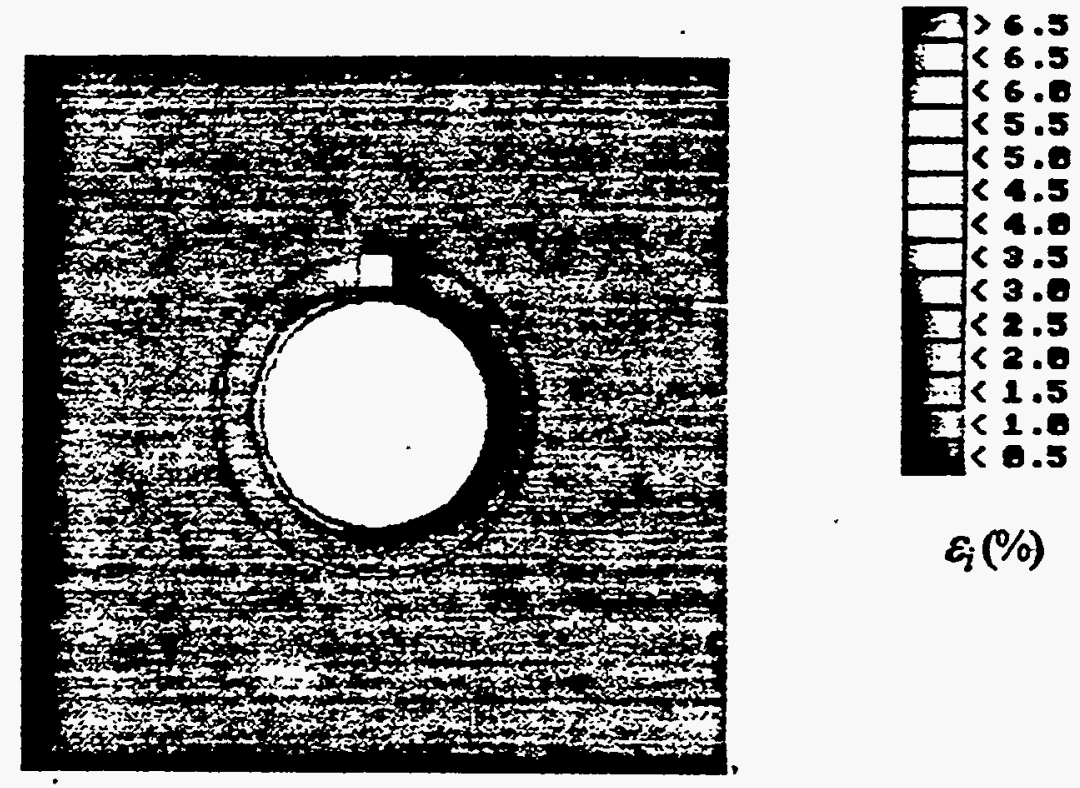

$$
\mathrm{t}=0 \mathrm{~ms}
$$

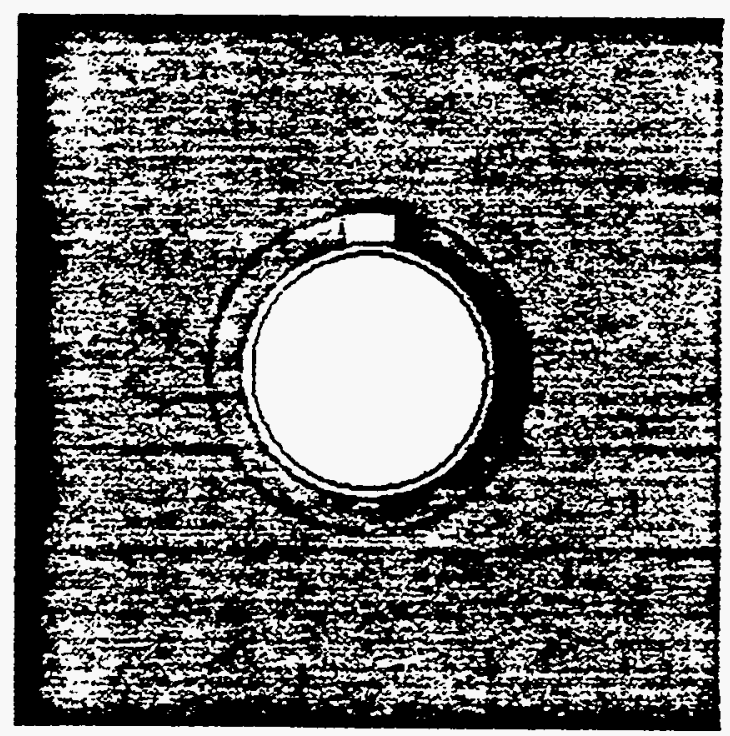

$$
t=0.6 \mathrm{~ms}
$$

Fig.12. Computed structure shapes for different times (computation 1 variant). 

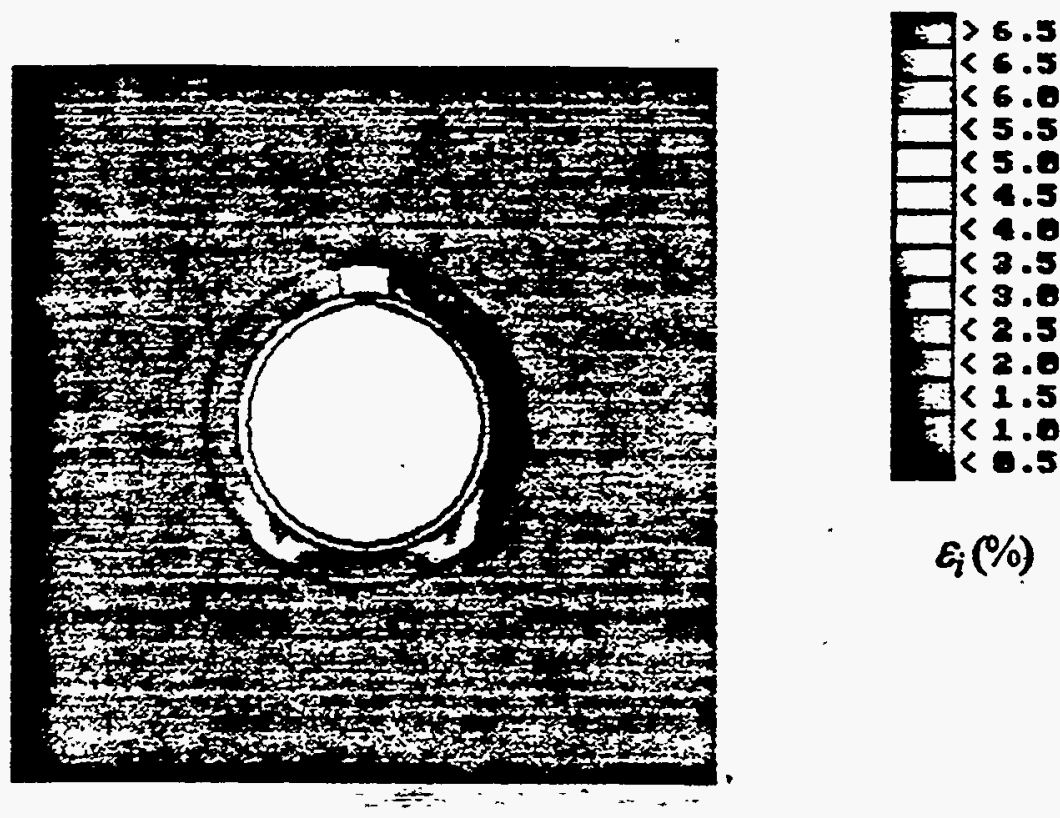

$\mathrm{t}=3.6 \mathrm{~ms}$

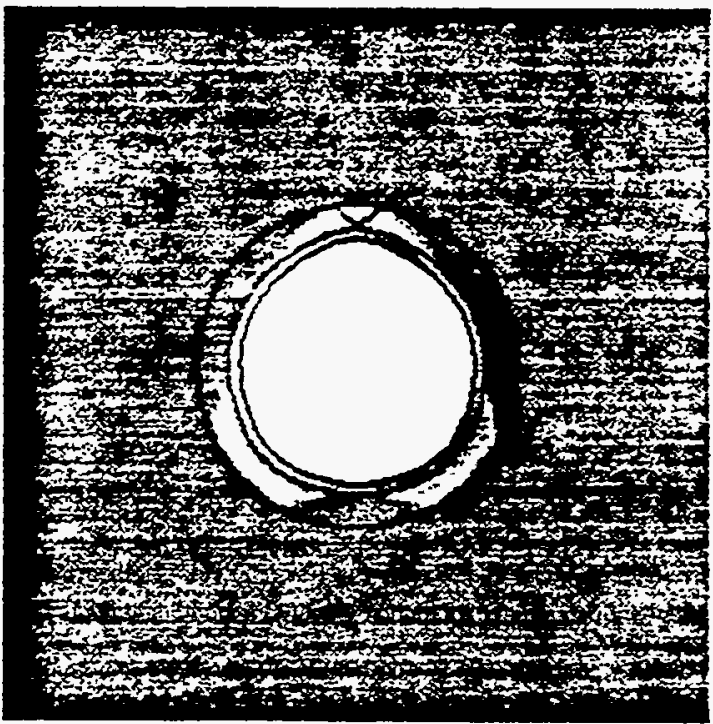

$\mathrm{t}=4.8 \mathrm{~ms}$

Fig.13. Computed structure shapes for different times (computation 1 variant). 
- (juetiea I uolpeinduros)

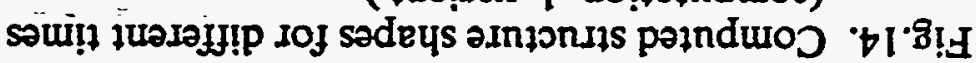

sw8:9=1

$(\%) 3$

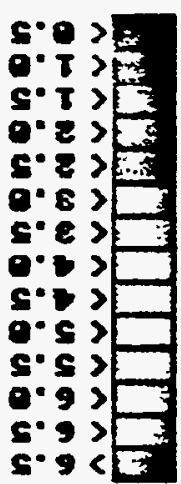

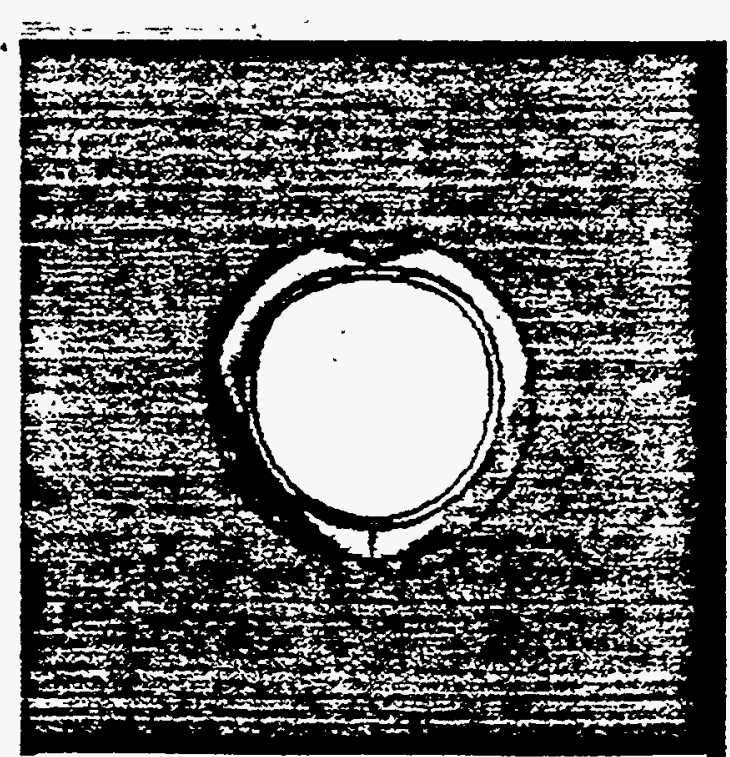




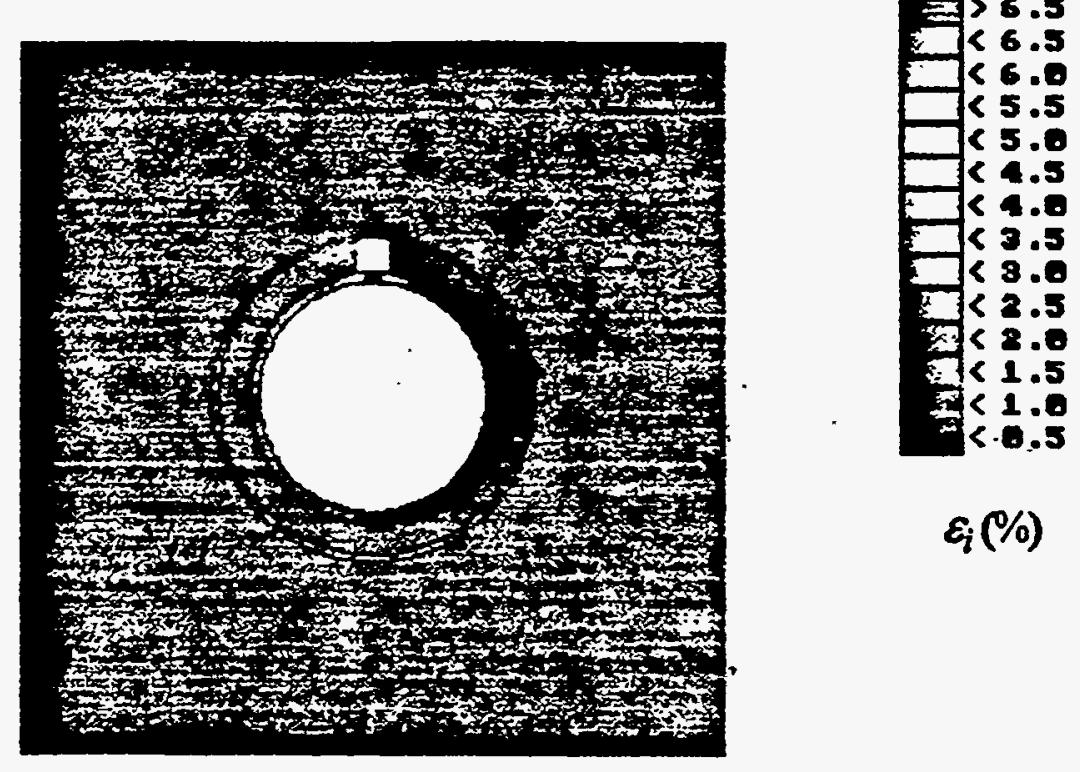

$\mathrm{t}=0 \mathrm{~ms}$

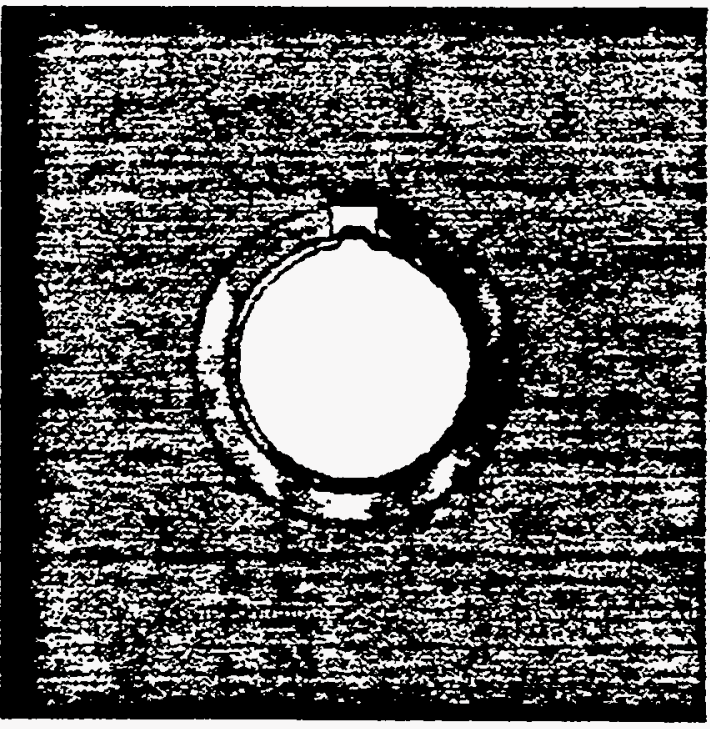

$\mathrm{t}=0.2 \mathrm{~ms}$

Fig.15. Computed structure shapes for different times (computation 2 variant). 

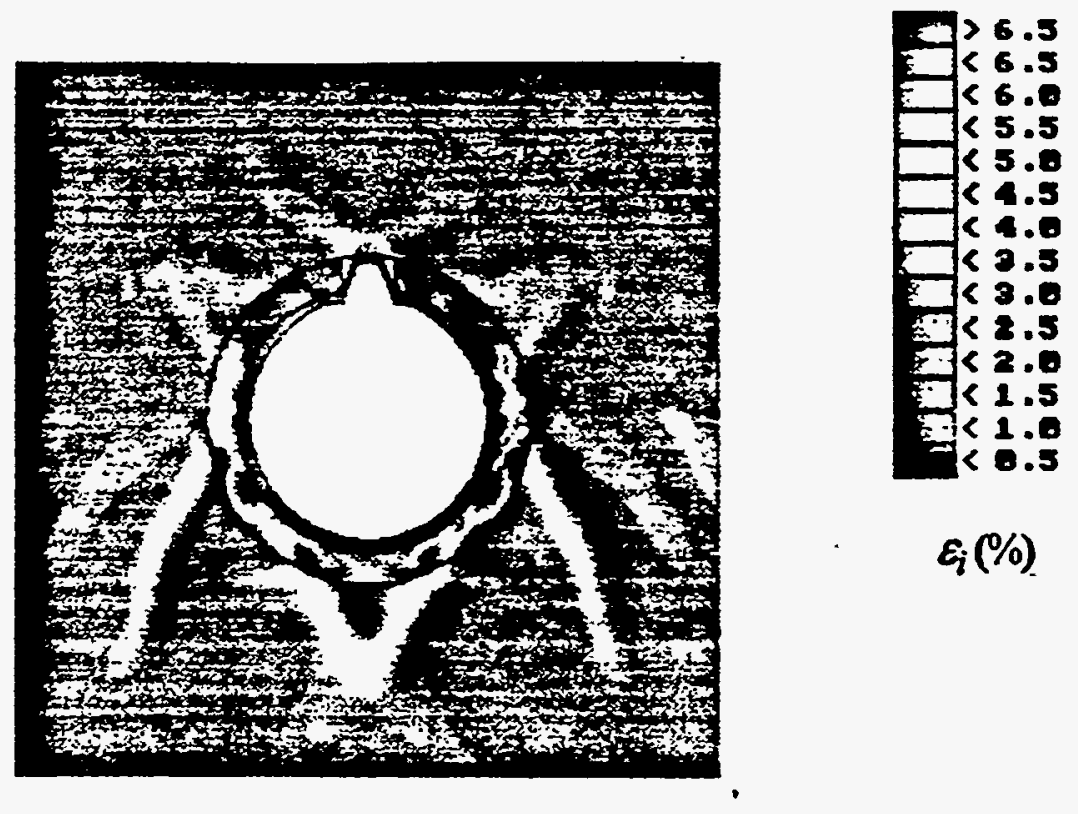

$\mathrm{t}=0.4 \mathrm{~ms}$

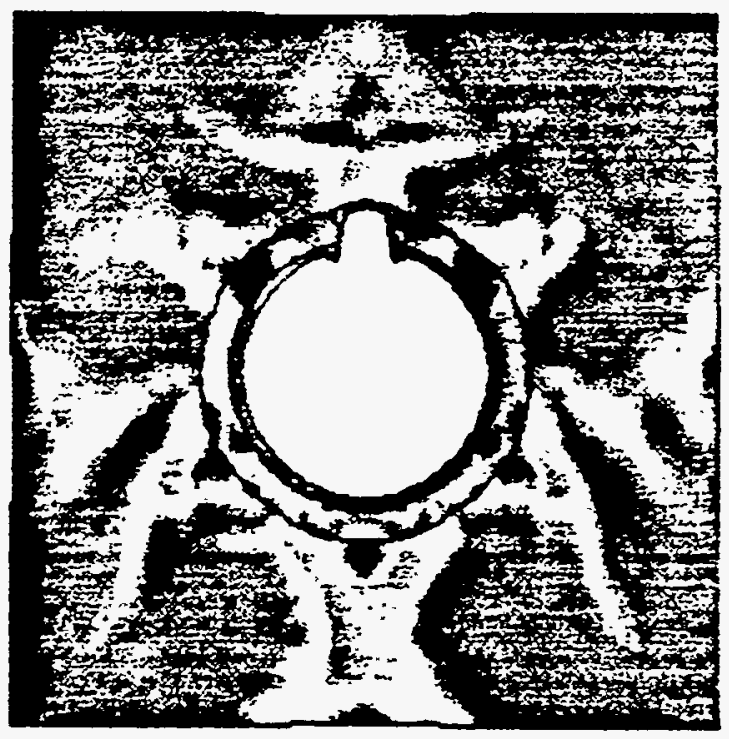

$\mathrm{t}=0.6 \mathrm{~ms}$

Fig.16. Computed structure shapes for different times (computation 2 variant). 

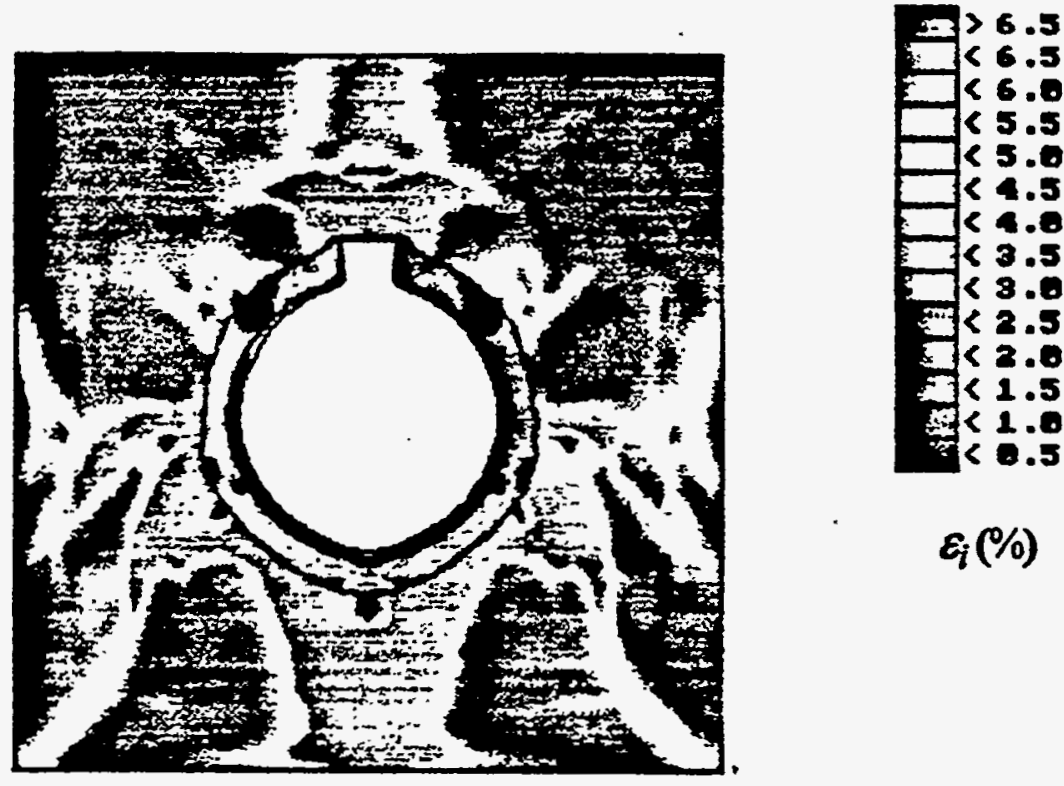

$\mathrm{t}=1.0 \mathrm{~ms}$

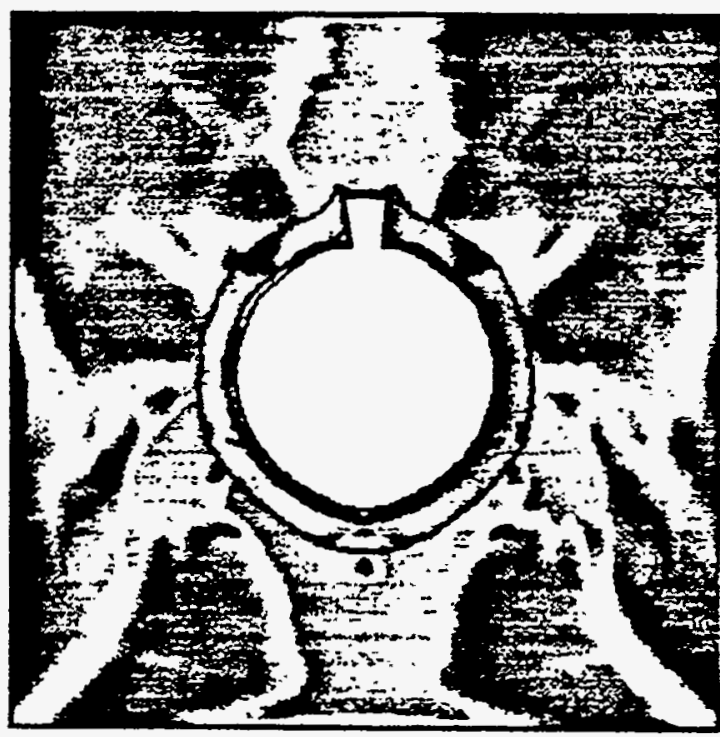

$\mathrm{t}=1.5 \mathrm{~ms}$

Fig.17. Computed structure shapes for different times (computation 2 variant). 

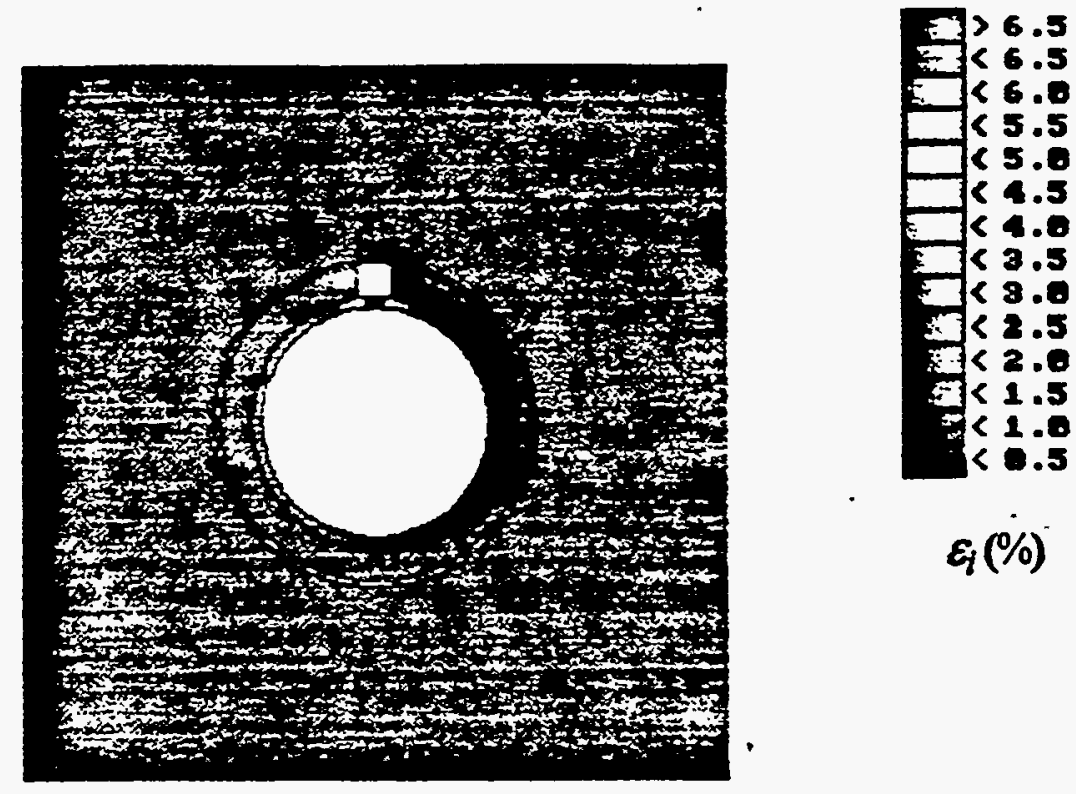

$\varepsilon_{1}(\%)$

$\mathrm{t}=0 \mathrm{~ms}$

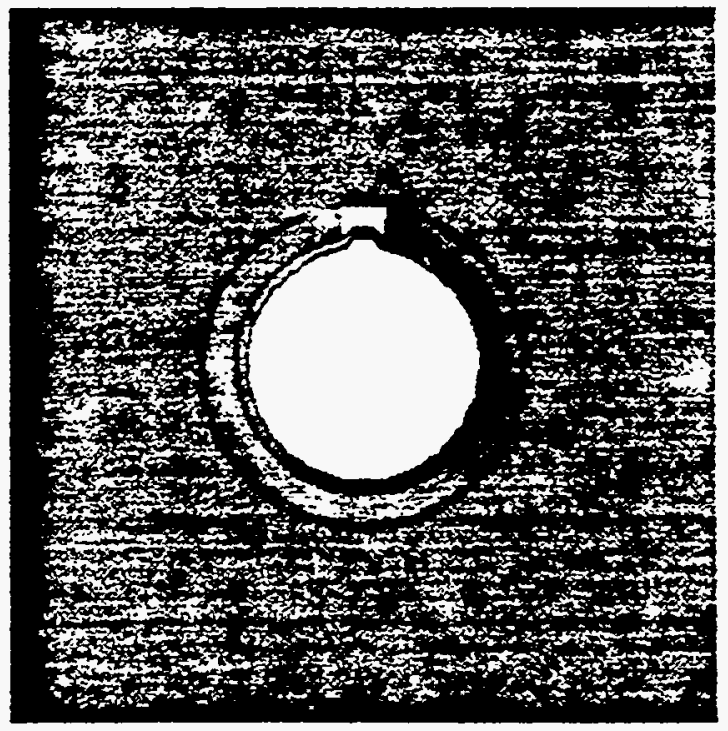

$\mathrm{t}=0.2 \mathrm{~ms}$

Fig.18. Computed structure shapes for different times (computation 3 variant). 

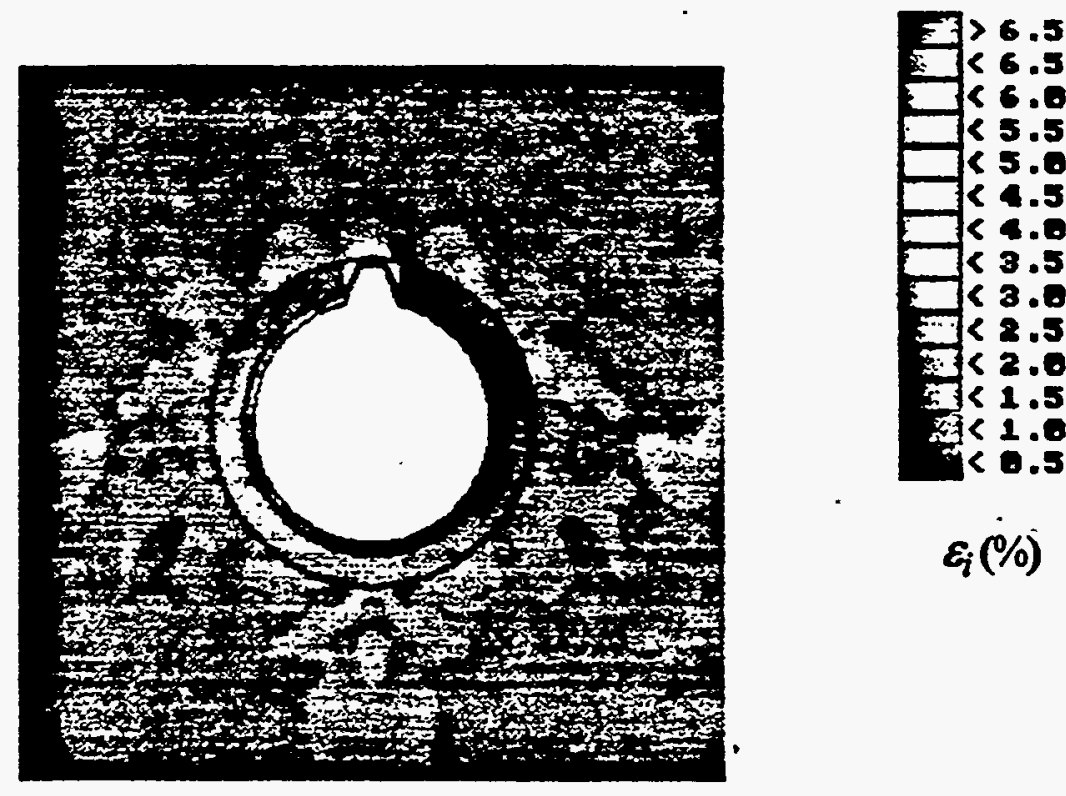

$\mathrm{t}=0.4 \mathrm{~ms}$

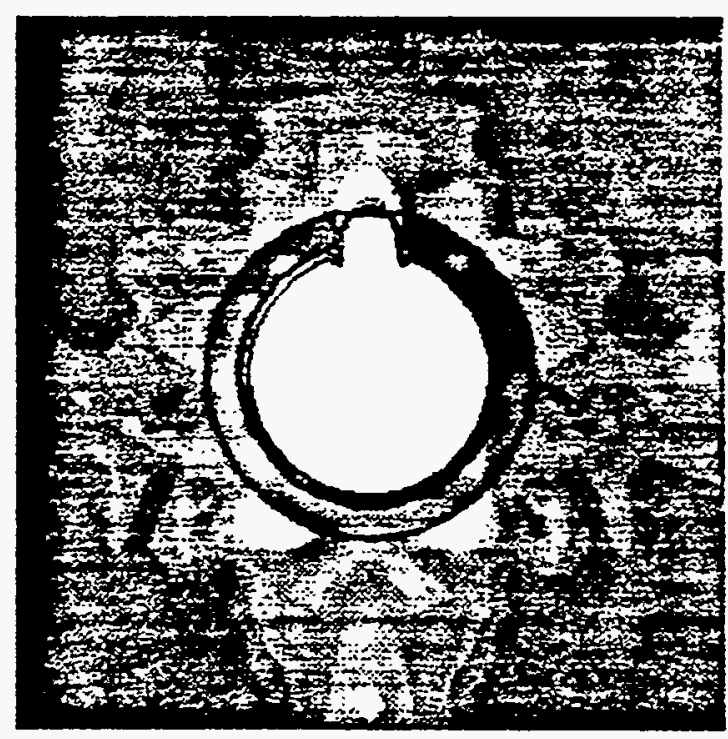

$\mathrm{t}=0.6 \mathrm{~ms}$

Fig.19. Computed structure shapes for different times (computation 3 variant). 

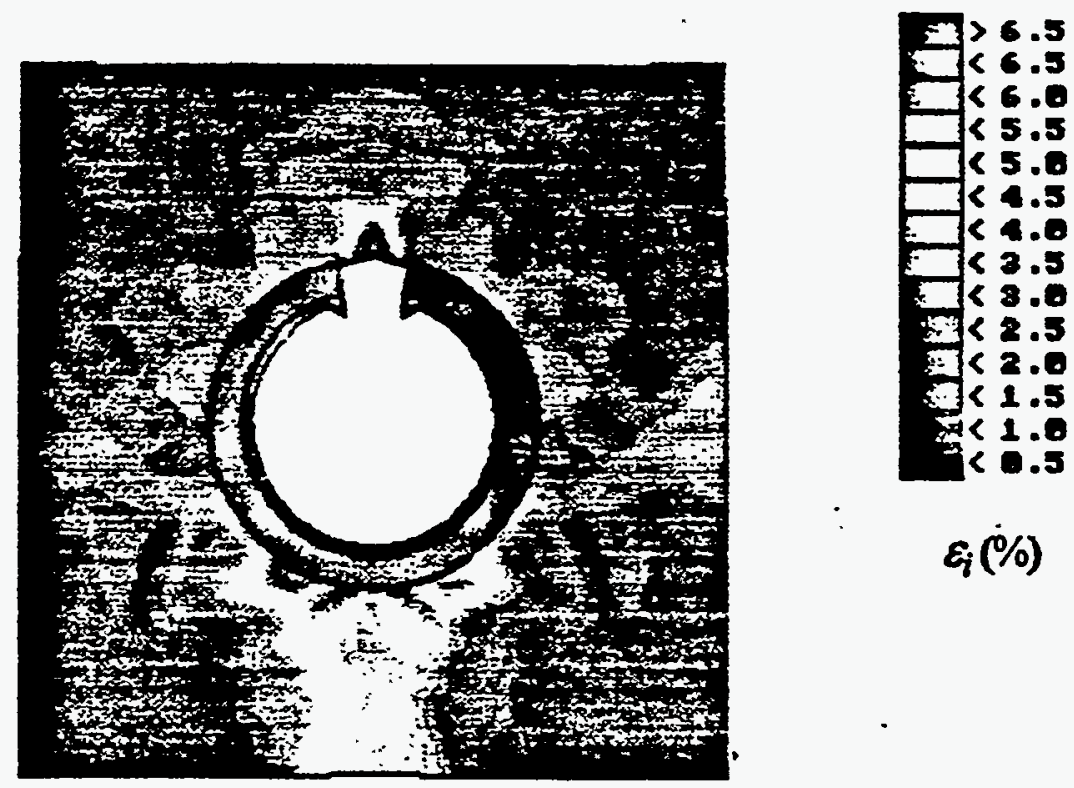

$\mathrm{t}=1.0 \mathrm{~ms}$

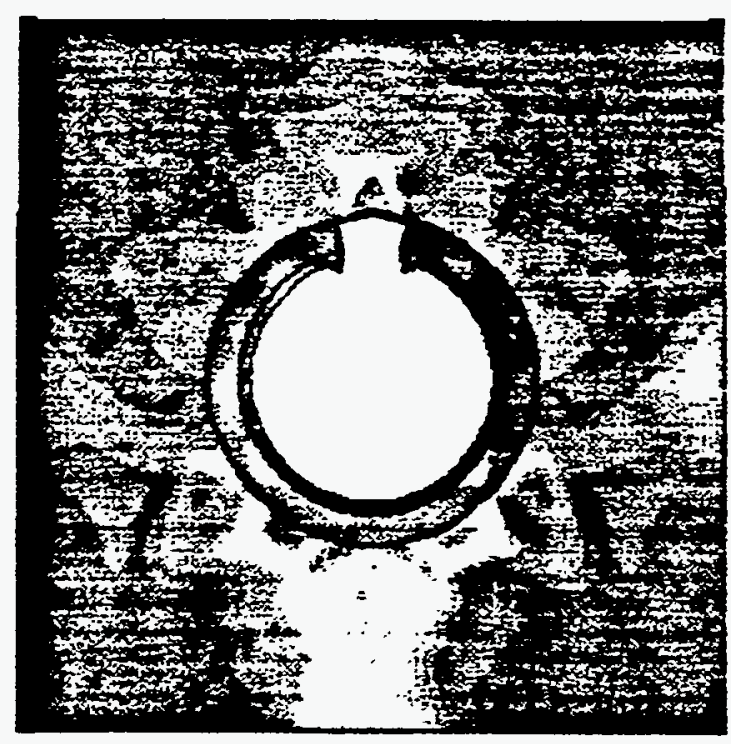

$\mathrm{t}=1.5 \mathrm{~ms}$

Fig.20. Computed structure shapes for different times (computation 3 variant). 


\section{CONCLUSION}

Numerical study was performed to estimate temperature and time characteristics of the initial stage of zirconium pipe rupture in an emergency related to abnormal rise in pipe temperature. The computations were performed using the DRAKON program complex $[3,4]$.

The geometric and physical - mechanical characteristics of elements depending on temperature were presented by NIKIET [2]. The temperature mode of the zirconium pipe was estimated with the RELAP5/MOD3 code [2].

As the numerical computation results showed, the limiting temperature value at which plastic flow of the zirconium pipe begins is $T \approx 665^{\circ} \mathrm{C}$. At the pipe ultimate strain value equal to $5 \%$ pipe rupture takes place in the region of the graphite ring joint. The graphite ring therewith ruptures and graphite slug continuity becomes broken. The rate of external slug scattering up to closure of the clearance with the neighboring slug is $\sim 3.2 \mathrm{~m} / \mathrm{s}$.

Essential dependence of the structure element strain character on ultimate strength characteristics of the zirconium pipe was found in the computations.

In view of the fact that the computations were performed using the strength characteristics estimated under the conditions of static strain the obtained numerical results are tentative and require further specification.

It should be noted that at this stage of numerical study we did not consider the issue of the effect on the graphite slug of steam jet which can be generated due to zirconium pipe rupture. 


\section{REFERENCES}

1. Protocol of the workshop on the RBMK reactor safety assesment using modern western computer codes. December 7-15, 1994 Los Alamos, New Mexico, USA.

2. Petrov A.A.,Baldin V.D.,Rodin V.D. Statement of Work for computation of RBMK reactor fuel channel rupture parameters, $4.854 \mathrm{TZ}$.

3. Pevnitsky A.V.,Tarasov V.A.,Solovyev V.P. et al. Review of VNIIEF computer programs used to study nuclear power facility safety. Report on the first phase of Task Order 007 under University of California-VNIIEF Subcontract N.0002P000495. 1994.

4. Pevnitsky A.B.,Tarasov V.A.,Solovyev V.P. et al . Report on the third phase of Task Order 007 under University of California-VNIIEF Subcontract $\$$.0002P0004-95. 1995. 